\title{
Clinical outcomes of single-level lumbar artificial disc replacement compared with transforaminal lumbar interbody fusion in an Asian population
}

\author{
Wei Ting $\underline{L e}^{1}$, MBBS, FRCSE, Gabriel $\underline{L i u}^{1}$, MBBCh, FRCSE, Joseph $\underline{\text { Thambiah }}{ }^{1}$, MBBS, FRCS, Hee Kit $\underline{\text { Wong }}{ }^{1}$, MBBS, FRCS
}

INTRODUCTION The objective of this study was to examine the clinical outcome of single-level lumbar artificial disc replacement (ADR) compared to that of transforaminal lumbar interbody fusion (TLIF) for the treatment of symptomatic degenerative disc disease (DDD) in an Asian population.

METHODS This was a retrospective review of 74 patients who had surgery performed for discogenic lower backs that involved only the L4/5 and L5/S1 levels. All the patients had lumbar DDD without radiculopathy or spondylolithesis, and concordant pain with discogram at the pathological level. The patients were divided into two groups - those who underwent ADR and those who underwent TLIF.

RESULTS A trend suggesting that the ADR group had better perioperative outcomes (less blood loss, shorter operating time, shorter hospital stay and shorter time to ambulation) than the TLIF group was observed. However, a trend indicating that surgical-approach-related complications occurred more frequently in the ADR group than the TLIF group was also observed. The rate of revision surgery was comparable between the two groups.

CONCLUSION Our findings suggest that for the treatment of discogenic lower back pain, lumbar ADR has better perioperative outcomes and a similar revision rate when compared with TLIF. However, the use of ADR was associated with a higher incidence of surgical-approach-related complications. More studies with bigger cohort sizes and longer follow-up periods are needed to determine the long-term efficacy and safety of ADR in lumbar DDD.

Keywords: artificial disc replacement, lumbar disc disease, patient outcome assessment, spinal fusion

\section{INTRODUCTION}

The treatment of symptomatic degenerative disc disease (DDD) is highly variable; it ranges from intensive rehabilitation to surgical stabilisation of the spine. ${ }^{(1)}$ Although there have been recent advancements in biological therapy and other novel surgical treatments, the treatment of symptomatic DDD remains challenging and highly controversial. ${ }^{(2)}$

Traditionally, spinal fusion is performed on patients with painful lumbar DDD who did not respond to conservative management. ${ }^{(3-5)}$ Removal of the disc and the subsequent fusion of the disc space eliminate the pain generator, leading to resolution of the pain. However, successful spinal fusion alters the biomechanical forces at the levels adjacent to the fusion site, thereby increasing the stress across the adjacent functional spinal units (FSUs). Artificial disc replacement (ADR) is designed to address the shortcomings of fusion surgery. It preserves and maintains normal motion in the FSUs adjacent to the fusion site. Preserving motion across the diseased spinal segments is desirable, as this would theoretically reduce the stress across the adjacent FSUs.

ADR is increasingly recognised as a viable treatment option to lumbar interbody fusion (LIF) for symptomatic DDD. ${ }^{(6,7)}$ While much has been published in the literature on the outcomes of ADR compared to those of LIF in Caucasian patients, ${ }^{(6-9)}$ few authors have published outcome studies based on Asian populations.
The objective of the present study was to compare the clinical outcomes of ADR with those of transforaminal LIF (TLIF) in Asian patients with symptomatic DDD.

\section{METHODS}

The present study was approved by the local ethics committee. The hospital records of all patients who underwent single-level lumbar ADR or TLIF between 2002 and 2007 were retrieved and analysed. Patients with lumbar DDD and pure chronic lower back pain without radiculopathy that involved only the $L 4 / 5$ spinal level or L5/S1 spinal level were included in the study. Each patient included had a discogram demonstrating concordant pain at the operated level. Patients who had multilevel disc involvement with concordant discogram pain at more than one level were excluded from the study. Patients were also excluded if they suffered from traumatic spine injuries, scoliosis, spondylolithesis, tumour and infection, and/or had surgeries involving spinal levels other than L4/5 and L5/S1.

The main selection criterion for patients undergoing ADR was isolated discogenic back pain with no clinical and magnetic resonance imaging evidence of facet disease. The risks and benefits of ADR and TLIF were explained to the patients prior to the surgery. Senior spine surgeons from the University Spine Centre, National University Hospital, Singapore, performed all the procedures in this study. 
A total of 74 patients matched the present study's inclusion criteria. These patients were divided into two groups, namely the ADR group and the TLIF group. Based on the department protocol, the patients were reviewed at two weeks, three months, six months, one year, two years and five years after surgery. Additional follow-up sessions were left to the discretion of the surgeon.

In this study, all the patients who underwent ADR had a ProDisc-L (Synthes, Paoli, PA, USA) inserted. The ProDisc-L design is based on the ball-and-socket principle and comprises three implant components - two cobalt chrome alloy endplates and an ultra-high-molecular-weight polyethylene inlay. The ProDisc-L endplates have central keels and small spikes for initial fixation of the artificial disc to the vertebral bodies, and plasma-sprayed titanium coatings on all bone-implant interfaces for better bony ingrowth and stability. ${ }^{(10)}$

All ADR surgeries were performed with the patient in the lithotomy position. In some cases, upon the request of the spine surgeons, access surgeons were employed for retroperitoneal dissection and vessel preparation. The operation was done via the retroperitoneal approach at the level of the affected lumbar disc. Upon exposure of the disc, a Cobb elevator was used to separate the cartilaginous endplates from the subchondral bone, and the disc material was removed in a piecemeal fashion. The posterior longitudinal ligament was also removed. After appropriate sizing, the ProDisc-L was inserted under fluoroscopic guidance.

TLIF was performed via the standard open midline posterior approach. After insertion of the pedicle screws, unilateral facetectomy was done and the ligamentum flavum was removed. Discectomy was performed between the exiting and traversing nerve roots. An LIF cage filled with local autogenous bone graft was then inserted into the disc space. Connecting rods were applied to the pedicle screws, and compression between the spinal segments was performed to complete the TLIF procedure.

\section{RESULTS}

Among the 74 patients included in the present study, 54 underwent ADR and 20 underwent TLIF. The mean age of the patients in the ADR group was significantly lower than that of the patients in the TLIF group (34 years vs. 52 years; $p<0.05$ ). A summary of the patients' characteristics is shown in Table I.

The ADR group was found to have a significantly shorter operating time $(p=0.04)$ (Table II). There was a trend toward less blood loss and shorter hospital stay among the patients in the ADR group as compared to those in the TLIF group, although the results did not reach statistical significance. The perioperative outcomes of the two groups are listed in Table II.

In the present study, $54(73.0 \%)$ patients (38 from the ADR group and 16 from the TLIF group) had follow-up for a minimum of two years. The TLIF group had a mean follow-up duration of 7.43 (range 3.7-10.2) years, while the ADR group had a mean follow-up duration of 4.92 (range 2.1-9.3) years. Patients who did not complete at least two years of follow-up were excluded from subsequent analyses on surgical-approach-related complications and rate of revision surgery.
Table I. Comparison of preoperative characteristics of the patients in the artificial disc replacement (ADR) group and the patients in the transforaminal lumbar interbody fusion (TLIF) group.

\begin{tabular}{lcc}
\hline Characteristic & \multicolumn{2}{c}{ No. of patients } \\
\cline { 2 - 3 } & ADR group (n = 54) & TLIF group ( $\mathbf{~ = ~ 2 0 ) ~}$ \\
\hline Age* $(\mathbf{y r})_{\text {Gender }}$ & & $52(37-70)$ \\
Male & 41 & 10 \\
Female & 13 & 10 \\
Surgery at L4/5 & 21 & 14 \\
Surgery at L5/S1 & 33 & 6 \\
\hline
\end{tabular}

*Data presented as mean (range).

Table II. Comparison of the perioperative outcomes of the patients in the artificial disc replacement (ADR) group and the patients in the transforaminal lumbar interbody fusion (TLIF) group.

\begin{tabular}{lccc}
\hline Perioperative outcome & $\begin{array}{c}\text { ADR group } \\
(\mathbf{n}=\mathbf{5 4})\end{array}$ & $\begin{array}{c}\text { TLIF group } \\
(\mathbf{n}=\mathbf{2 0})\end{array}$ & \\
\hline Mean operating time (min) & 185.6 & 215.3 & $0.04^{*}$ \\
Mean drop in haemoglobin (g/dL) & 1.8 & 2.3 & 0.38 \\
Mean length of hospital stay (day) & 6.1 & 6.5 & 0.21 \\
Mean time to ambulation (day) & 2.9 & 3.6 & 0.07 \\
\hline
\end{tabular}

${ }^{*} \mathrm{p}$-value $<0.05$ is considered statistically significant

Surgical-approach-related complications were the most common complications encountered in the present study. The rate of surgical-approach-related complications in the ADR group was $16.7 \%$, while that in the TLIF group was $5.0 \%(p=0.192)$. Complications included peritoneal injuries $(n=5 ; 9.3 \%)$, superficial abdominal infection $(n=3 ; 5.6 \%)$ and retrograde ejaculation $(n=1 ; 1.9 \%)$. There was a single case of dura tear recorded during a TLIF procedure.

Patients with at least two years of follow-up $(n=54)$ were analysed for the rate of revision surgery. The rate of revision surgery in the ADR group was 4 (10.5\%), while that in the TLIF group was $2(12.5 \%)(p=0.833)$. In the ADR group, one patient had facet osteoarthritis at the initial ADR level, while the other three patients complained of pain in the adjacent spinal levels. All four patients complained of persistent back pain after the initial ADR surgery. In the TLIF group, two patients developed painful spinal pathologies at the adjacent spinal levels after a pain-free interval. A summary of the revision surgeries is presented in Table III.

\section{DISCUSSION}

The treatment goal for discogenic back pain is to remove the pain generator in the disc. This can be achieved either by replacing the diseased disc or by fusing the FSUs. Experiences from knee and hip replacement surgeries indicate that patients generally do better after joint replacement surgeries as compared to fusion surgeries. Also, as preserving motion across the diseased spinal segment is desirable and fusion increases the stress across the adjacent FSUs, replacement surgeries are generally favoured over fusion surgeries. Adjacent segment disease is also a problem for fusion patients. In a study of 149 patients who underwent LIF, Gillet found that $41 \%$ of the patients developed abnormal adjacent 
Table III. Summary of the revision surgeries conducted on the patients in the artificial disc replacement (ADR) group and the transforaminal lumbar interbody fusion (TLIF) group.

\begin{tabular}{|c|c|c|c|c|c|c|}
\hline Patient & $\begin{array}{l}\text { Initial } \\
\text { operation }\end{array}$ & $\begin{array}{l}\text { Pain-free } \\
\text { interval }\end{array}$ & $\begin{array}{l}\text { Revision } \\
\text { operation }\end{array}$ & Pathological findings & $\begin{array}{l}\text { Post-revision } \\
\text { status }\end{array}$ & Remarks \\
\hline ADR 1 & L4/5 ADR & $1 \mathrm{yr}$ & L4/5 TLIF & $\begin{array}{l}\text { L4/5 facet osteoarthritis } \\
\text { on CT image }\end{array}$ & $\begin{array}{l}\text { Pain-free at } \\
\text { last follow-up }\end{array}$ & Patient responded to $L 4 / 5$ facet block \\
\hline ADR 2 & L4/5 ADR & $6 \mathrm{mth}$ & L5/S1 ADR & L5/S1 DDD & $\begin{array}{l}\text { Pain-free at } \\
\text { last follow-up }\end{array}$ & $\begin{array}{l}\text { Initial preoperative MR image showed } L 4 / 5 \\
\text { and L5/S1 DDD, with concordant pain at } L 4 / 5\end{array}$ \\
\hline ADR 3 & L4/5 ADR & $6 \mathrm{mth}$ & $\begin{array}{l}\text { L4/5 posterior } \\
\text { decompression, } \\
\text { L5/S1 TLIF }\end{array}$ & $\begin{array}{l}\text { L5/S1 facet osteoarthritis, } \\
\text { L4/5 facet osteoarthritis } \\
\text { and scar tissue }\end{array}$ & $\begin{array}{l}\text { Pain-free at } \\
\text { last follow-up }\end{array}$ & $\begin{array}{l}\text { Initial postoperative MR image showed facet } \\
\text { joint osteoarthritis and scar tissue at L4/5, } \\
\text { and L5/S1 facet osteoarthritis }\end{array}$ \\
\hline ADR 4 & L4/5 ADR & $2 w k$ & L5/S1 TLIF & L5/S1 spondylolithesis & $\begin{array}{l}\text { Persistent pain } \\
\text { after revision } \\
\text { operation }\end{array}$ & $\begin{array}{l}\text { Patient underwent } \mathrm{L} 3 / 4 \text { and left } \mathrm{L} 2 \text { medial } \\
\text { branch block for additional pain control two } \\
\text { years after the revision operation }\end{array}$ \\
\hline TLIF 1 & L4/5 TLIF & $4 \mathrm{yr}$ & L3/4 TLIF & L3/4 DDD & $\begin{array}{l}\text { Pain-free at } \\
\text { last follow-up }\end{array}$ & - \\
\hline
\end{tabular}

CT: computed tomography; DDD: degenerative disc disease; MR: magnetic resonance

lumbar motion segments after spinal fusion and $20 \%$ needed a secondary operation for extension of the fusion. ${ }^{(11)}$

The efficacy of ADR in preserving spinal motion is well documented in the literature. In a prospective, randomised trial of 237 patients, which compared two-level ADR with circumferential arthrodesis, Delamarter et al noted preservation of the lumbar flexion-extension motion after ADR. ${ }^{(12)}$ The range of motion of the superior and inferior discs on radiographic examination averaged $7.8^{\circ}$ and $6.2^{\circ}$, respectively. ${ }^{(12)}$ Similarly, Zigler et al observed improved postoperative forward and lateral bending on clinical examination of the patients from the ADR group as compared to those from the fusion group. ${ }^{(13)}$ Huang et al studied the correlation between the range of motion of the lumbar spine and clinical outcomes in 38 patients who underwent ADR with PRODISC I; they demonstrated weak to moderate Spearman rank correlation association between the range of motion and clinical outcomes. ${ }^{(14)}$ Compared to spinal fusion surgery, the motion-preserving ability of ADR can potentially decrease adjacent spine segments disease..$^{(8,15}$

Other than preserving motion in the spine, ADR has many other advantages over fusion surgery in the treatment of lumbar spinal pathologies (e.g. avoiding surgical complications that are associated with posterior surgical approaches and the use of iliac crest bone grafts). ${ }^{(9,13,16)}$ In addition, ADR has been shown to be an efficient treatment modality in symptomatic DDD in both short- and mid-term studies. ${ }^{(17-20)}$ Zigler et al observed better early outcomes and earlier ambulatory status in patients who underwent $A D R$ as compared to those who underwent lumbar fusion. ${ }^{(13)}$ In a meta-analysis of ADR versus fusion for lumbar DDD, Yajun et al also noted better postoperative functional status (with less back and leg pain) and higher satisfaction rates in the ADR group than in the lumbar fusion group at the two-year follow-up. ${ }^{(21)}$ As the measures of disability, pain and neurological status were similarly improved from baseline in both the ADR and TLIF groups at five years after treatment, some authors have concluded that ADR surgery using ProDisc- $L$ was not inferior to fusion surgery in the treatment of single-level lumbar DDD. ${ }^{(22)}$

Although the short- and mid-term results of ADR have been shown to be positive, the long-term benefit of ADR surgery over fusion surgery in lumbar DDD has not been proven conclusively. While patients with chronic discogenic back pain treated with ADR surgery have shown small but statistically significant clinical improvements as compared to those treated with fusion surgery, these improvements may not be clinically relevant. ${ }^{(23)}$ In addition, there is a lack of information on the effect ADR surgery has on adjacent disc disease in current trials that compare ADR surgery with fusion surgery. These shortcomings may limit the widespread use of ADR in the treatment of chronic lower back pain.

The rate of surgical-approach-related complications in ADR ranged from $2.1 \%$ to $18.7 \%$, while reoperation at the index level ranged from $1.0 \%$ to $28.6 \% .{ }^{(24)}$ In the present study, there was a trend toward more surgical-approach-related complications in the ADR group (16.7\%) as compared to the TLIF group (5.0\%). The higher surgical-approach complication rate could have been due to the steep learning curve of ADR surgery. In other words, the higher surgical-approach complication rate could possibly have been reduced with more surgical experience and/or the use of a dedicated group of access surgeons.

In the present study, the surgical revision rate was similar between the ADR group and the TLIF group (10.5\% vs. $12.5 \%$, $p=0.833)$. These revision surgeries were mainly due to long-term spinal pathology progression (e.g. adjacent motion segment disease and facet arthropathy) or spinal pathologies that were inadequately treated initially. Our data suggested that the recurrence of lower back pain in the ADR group generally occurred within the first operative year, whereas patients in the TLIF group generally remained well for the first few years. Further studies are needed to elucidate the root cause for reoperation at the index level.

Ultimately, the key to a successful outcome in surgically treated patients with lumbar DDD lies in careful patient selection; this is true for both TLIF and ADR surgeries. Unlike TLIF, ADR targets the painful disc. As ADR cannot address spinal pathologies such as instability and facet arthropathy, the ideal candidate for ADR should have a single black disc on magnetic resonance imaging, with concordant disc pain, and no evidence of facet 
joint arthropathy. Unfortunately, due to the imprecise nature of identifying pain generators in the spine, ${ }^{(25,26)}$ patient selection can be challenging. It is difficult to predict with certainty which patient will respond positively to ADR surgery. In the present study, ADR patients 1 and 3 (Table III) exemplified how challenging it is to identify pain generators in the spine. Both of these patients continued to have pain at the operated level, even after ADR, due to underlying facet osteoarthritis.

One major limitation of the present study is the significant difference in the mean ages of the patients in the ADR group and the TLIF group; on average, patients in the ADR group were younger than those in the TLIF group. Generally, motion-sparing surgery in the lumbar spine is performed in younger patients and this accounted for the disparity in the mean ages of the two groups. The other limitation is the small cohort size. While the cohort size was larger than the 58 patients required based on power analysis, ${ }^{(27)}$ only $54(73.0 \%)$ patients were included in the final analysis, as some were lost to follow-up. Despite these limitations, the present study is the first to compare ADR surgery with TLIF surgery for discogenic back pain in an Asian population.

In conclusion, while the use of ADR was associated with shorter operating time and a trend toward less blood loss and shorter hospital stay, there was a trend toward more surgicalapproach-related complications. As the latter is possibly due to a lack of experience in exposing the anterior spinal column, the use of a dedicated group of access surgeons should be considered. For the treatment of discogenic back pain, ADR was found to be as effective as TLIF in carefully selected patients; the rates of reoperation at the index level for the two groups were comparable. The long-term benefits of ADR in preventing adjacent level disc degeneration remain unproven. Additional studies with larger cohort sizes and longer follow-up periods are required to determine the long-term efficacy and safety of ADR in lumbar DDD.

\section{REFERENCES}

1. Chou R, Baisden J, Carragee EJ, et al. Surgery for low back pain: a review of the evidence for an American Pain Society Clinical Practice Guideline. Spine (Phila Pa 1976) 2009; 34:1094-109.

2. Hughes SP, Freemont AJ, Hukins DW, McGregor AH, Roberts S. The pathogenesis of degeneration of the intervertebral disc and emerging therapies in the management of back pain. J Bone Joint Surg Br 2012; 94:1298-304.

3. Kwon B, Katz JN, Kim DH, Jenis LG. A review of the 2001 Volvo Award winner in clinical studies: lumbar fusion versus nonsurgical treatment for chronic low back pain: a multicenter randomized controlled trial from the Swedish lumbar spine study group. Spine (Phila Pa 1976) 2006; 31:245-9.

4. Fritzell P, Hägg O, Wessberg P, Nordwall A; Swedish Lumbar Spine Study Group. Chronic low back pain and fusion: a comparison of three surgical techniques: a prospective multicenter randomized study from the Swedish lumbar spine study group. Spine (Phila Pa 1976) 2002; 27:1131-41.

5. Moore KR, Pinto MR, Butler LM. Degenerative disc disease treated with combined anterior and posterior arthrodesis and posterior instrumentation. Spine (Phila Pa 1976) 2002; 27:1680-6.

6. Guyer RD, McAfee PC, Banco RJ, et al. Prospective, randomized, multicenter Food and Drug Administration investigational device exemption study of lumbar total disc replacement with the CHARITE artificial disc versus lumbar fusion: five-year follow-up. Spine J 2009; 9:374-86.
7. Wei J, Song Y, Sun L, Lv C. Comparison of artificial total disc replacement versus fusion for lumbar degenerative disc disease: a meta-analysis of randomized controlled trials. Int Orthop 2013; 37:1315-25.

8. Zigler JE, Glenn J, Delamarter RB. Five-year adjacent-level degenerative changes in patients with single-level disease treated using lumbar total disc replacement with ProDisc-L versus circumferential fusion. J Neurosurg Spine 2012; 17:504-11.

9. Freeman BJ, Davenport J. Total disc replacement in the lumbar spine: a systematic review of the literature. Eur Spine J 2006; 15 Suppl 3:S439-47.

10. ProDisc-L Total Disc Replacement. For replacement of a diseased and/ or degenerated intervertebral disc of the lumbosacral region. Technique Guide. In: Synthes, Inc. [online] Available at: http://www.synthes.com/ MediaBin/US DATA/Product Support Materials/Technique Guides/ SPTGProDisc-LJ6206D.pdf. Accessed January 21, 2015.

11. Gillet P. The fate of the adjacent motion segments after lumbar fusion. J Spinal Disord Tech 2003; 16:338-45.

12. Delamarter R, Zigler JE, Balderston RA, et al. Prospective, randomized, multicenter Food and Drug Administration investigational device exemption study of the ProDisc- $L$ total disc replacement compared with circumferential arthrodesis for the treatment of two-level lumbar degenerative disc disease: results at twenty-four months. J Bone Joint Surg Am 2011; 93:705-15.

13. Zigler JE, Burd TA, Vialle EN, et al. Lumbar spine arthroplasty: early results using the ProDisc II: a prospective randomized trial of arthroplasty versus fusion. J Spinal Disord Tech 2003; 16:352-61.

14. Huang RC, Girardi FP, Cammisa FP Jr, et al. Correlation between range of motion and outcome after lumbar total disc replacement: 8.6-year followup. Spine (Phila Pa 1976) 2005; 30:1407-11.

15. David T. Long-term results of one-level lumbar arthroplasty: minimum 10-year follow-up of the CHARITE artificial disc in 106 patients. Spine (Phila Pa 1976) 2007; 32:661-6.

16. Summers BN, Eisenstein SM. Donor site pain from the ilium. A complication of lumbar spine fusion. J Bone Joint Surg Br 1989; 71:677-80.

17. Griffith SL, Shelokov AP, Büttner-Janz K, LeMaire JP, Zeegers WS. A multicenter retrospective study of the clinical results of the LINK SB Charité intervertebral prosthesis. The initial European experience. Spine (Phila Pa 1976) 1994; 19:1842-9.

18. Cinotti G, David T, Postacchini F. Results of disc prosthesis after a minimum follow-up period of 2 years. Spine (Phila Pa 1976) 1996; 21:995-1000.

19. Zeegers WS, Bohnen LM, Laaper M, Verhaegen MJ. Artificial disc replacement with the modular type SB Charité III: 2-year results in 50 prospectively studied patients. Eur Spine J 1999; 8:210-7.

20. Hopf C, Heeckt H, Beske C. [Disc replacement with the SB Charité endoposthesis - experience, preliminary results and comments after 35 prospectively performed operations]. Z Orthop Ihre Grenzgeb 2002; 140:485-91. German.

21. Yajun W, Yue Z, Xiuxin H, Cui C. A meta-analysis of artificial total disc replacement versus fusion for lumbar degenerative disc disease. Eur Spine J 2010; 19:1250-61.

22. Zigler JE, Delamarter RB. Five-year results of the prospective, randomized, multicenter, Food and Drug Administration investigational device exemption study of the ProDisc-L total disc replacement versus circumferential arthrodesis for the treatment of single-level degenerative disc disease. J Neurosurg Spine 2012; 17:493-501.

23. Jacobs WC, van der Gaag NA, Kruyt MC, et al. Total disc replacement for chronic discogenic low back pain: a Cochrane review. Spine (Phila Pa 1976) $2013 ; 38: 24-36$.

24. van den Eerenbeemt KD, Ostelo RW, van Royen BJ, Peul WC, van Tulder MW. Total disc replacement surgery for symptomatic degenerative lumbar disc disease: a systematic review of the literature. Eur Spine J 2010; 19:1262-80

25. Janssen M, Nabih A, Moussa W, Kawchuk GN, Carey JP. Evaluation of diagnosis techniques used for spinal injury related back pain. Pain Res Treat 2011; 2011:478798.

26. Endean A, Palmer KT, Coggon D. Potential of magnetic resonance imaging findings to refine case definition for mechanical low back pain in epidemiological studies: a systematic review. Spine (Phila Pa 1976) 2011; 36:160-9.

27. Faul F, Erdfelder E, Buchner A, Lang AG. Statistical power analyses using G*Power 3.1: tests for correlation and regression analyses. Behav Res Methods 2009; 41:1149-60. 